\title{
A Cox Proportional Hazard Model Approach to Age at First Sexual Intercourse in Nigeria
}

\author{
Chukwudi Paul Obite ${ }^{*}$, Desmond Chekwube Bartholomew ${ }^{1}$, Iheoma Blessing Duru ${ }^{1}$, \\ Joan Ismaila-Cosmos ${ }^{2}$, Chidiebere Chukwuemeka²
}

${ }^{1}$ Department of Statistics, Federal University of Technology, Owerri, Nigeria

${ }^{2}$ Department of Mathematics and Statistics, University of Port Harcourt, Port Harcourt, Nigeria

Email: *chukwudi.obite@futo.edu.ng

How to cite this paper: Obite, C.P., Bartholomew, D.C., Duru, I.B., Ismaila-Cosmos, J. and Chukwuemeka, C. (2020) A Cox Proportional Hazard Model Approach to Age at First Sexual Intercourse in Nigeria. Open Journal of Statistics, 10, 252-260. https://doi.org/10.4236/ojs.2020.102018

Received: February 18, 2020

Accepted: April 7, 2020

Published: April 10, 2020

Copyright $\odot 2020$ by author(s) and Scientific Research Publishing Inc. This work is licensed under the Creative Commons Attribution International License (CC BY 4.0).

http://creativecommons.org/licenses/by/4.0/

\begin{abstract}
Early age at first sexual intercourse comes with many negative sexual outcomes namely: having unprotected sex on first sexual intercourse, condom misuse, high rate of sexually transmitted infections (STIs), teenage pregnancy, increased number of sexual partners, etc. In this paper, we considered some socio-demographic and cultural factors and their relationship with age at first sexual intercourse so as to reduce the numerous negative sexual outcomes of early age at first sexual intercourse using the 2018 Nigerian Demographic and Health Survey data. The analysis was made using the Cox proportional hazard model and the Kaplan-Meier plot. The result shows that some respondents started having their first sexual intercourse at the age of 8 years and about $54.4 \%$ of the respondents had their first sexual intercourse before age 17 years. The median age of first sexual intercourse is 16 years which implies that about $50 \%$ of the respondents had their first sexual intercourse on or before their $16^{\text {th }}$ birthday. Education, religion, region and residence significantly affects the age of first sexual intercourse while circumcision has no significant effect.
\end{abstract}

\section{Keywords}

Sexual Intercourse, Socio-Demographic and Cultural Factors, Hazard Rate, Cox Proportional Hazard Model

\section{Introduction}

Age at first sex is the age at which an individual is involved in his first sexual intercourse. Early age at first sexual intercourse is an important event for public health policy makers as it has many consequences [1]. Adolescent girls who have their first intercourse at earlier ages are prone to a variety of negative sexual health outcomes which includes: having unprotected sex on first sexual inter- 
course, condom misuse, high rate of sexually transmitted infections (STIs), teenage pregnancy, increased number of sexual partners, persistence experience with intimate partner violence and adverse psychological consequences which makes them live in regret and disappointment [2] [3] [4] [5] [6]. Early age at first sexual intercourse makes the individual to be sexually active and end up having concurrent sexual partnerships. Having multiple concurrent sexual partners increases the risk of transmission of a sexually transmitted infection and in cases when the sexual partnerships do not overlap but the gap between partnerships is shorter than the infectious periods, transmission potential will still exist. Some socio-demographic and cultural factors can contribute positively or negatively to early age at first sexual intercourse and this study seeks to identify some of these factors so as to reduce the numerous negative sexual health outcomes of early age at first sexual intercourse.

Mercer et al. [7] quantified the gap between partners to assess transmission potential by issuing out questionnaires with questions about the respondents' three most recent partnerships. They used a cross-sectional survey of 2,203 genitourinary medicine clinic patients in England in 2009. Although half of the gaps were positive (serially monogamous partnerships), many were of short duration and condoms were either used inconsistently with one or both partners or no condom was used by either partner. There result showed that there is a high potential for sexually transmitted infections. Even if the partners are not behaviorally concurrent, they may still be biologically concurrent. Anne [8] studied the rate of entry into sexual relations using the 1998 South African Demographic and Health Survey. Her result showed that about $18 \%$ of the respondents had sex by age 15 , the median age at time of first sex was approximately 18 years and virtually all the women had sex by age 23 . She went further to compare her findings with the findings from Tanzania and Zimbabwe. It appeared that South Africans tend to enter sexual relationships later than Tanzanian and more or less at the same stage as Zimbabweans.

Laura et al. [9] examined the prevalence of sexual intercourse before age 13 years among male adolescents; the variation of sexual intercourse by ethnicity, location and maternal education; the rate at which they wanted this first sexual intercourse; and the associations between first sexual intercourse and socio-economic covariates. About $7.6 \%$ of those age 13 years and below were found to have had their first sexual intercourse and respondents whose mothers had a college degree or higher educational level were statistically significantly less likely to have their first sexual intercourse before age 13 years compared with those whose mothers did not have a college degree. About $8.5 \%$ of those that had their first sexual intercourse before age 13 years described their sexual intercourse as unwanted. They also found out that early age at first sex had a significant relationship with ethnicity and location of the respondents. Research showed that males are more than twice as likely as females to experience first sexual intercourse before age 13 years [10] and the timing of first sexual intercourse for those in urban and rural is significantly different [11]. 
Lorraine et al. [12] explored relationships between contextual socio-demographic, health and lifestyle factors and the timing of first sexual intercourse among those aged 15 - 17 years in Ireland. The socio-demographic and lifestyle factors were a stronger predictor of age of sexual initiation among girls than boys. Risk behaviour initiation was significantly related to age of sexual initiation for adolescents. Alcohol use and unhealthy food consumption was significant for only girls while family support and number of male friends were significant predictors for boys only. Children are significantly more likely to become sexually active before age 14 if their mother had sex at an early age and if she has worked extensively [13]. Also from [13] findings, early sexual intercourse is eight times as likely among black boys as among non-Hispanic white boys and church attendance delays sexual activity. Males who take alcohol and females who smoke at an early age are more than twice as likely to have sex before age 14 as those who do not.

\section{Methodology}

The data used for this study is a secondary data from the 2018 Nigerian Demographic and Health Survey of 8061 respondents. Five categorical explanatory variables were considered to study their effect on age at first sex. The censoring nature of the data made us to use Cox Proportional Hazard Model to analyse the effects of the factors on age at first sex. Some of the respondents in the study were censored since they did not have the event of interest-first sex.

\subsection{The Cox Model}

The Cox proportional hazard model also known as Cox model is a semi parametric model commonly used in medical research for investigating the association between survival time of respondents and one or more predictor variables. The Cox model allows us to examine how specified factors influence the rate of a particular event happening at a particular point in time. The rate is also known as the hazard rate and the predictory variables as covariates. The Cox model is given below

$$
h(t)=h_{0}(t) \times \exp \left(b_{1} x_{1}+b_{2} x_{2}+\cdots+b_{p} x_{p}\right)
$$

where,

$\mathrm{t}$ is the survival time;

$h(t)$ is the hazard function;

$b_{p}$ are the coefficients that measures the impact of the $\mathrm{p}$-covariates;

$h_{0}(t)$ is the baseline hazard. It is the value of the hazard if all the $x_{i}$ are equal to zero.

Equation (1) can also be written as a Multiple Linear Regression of the logarithm of the hazard on the covariates with the baseline hazard being an intercept term that varies with time as shown below:

$$
\begin{gathered}
\log _{e}(h(t))=\log _{e}\left[h_{0}(t) \times \exp \left(b_{1} x_{1}+b_{2} x_{2}+\cdots+b_{p} x_{p}\right)\right] \\
\log _{e}(h(t))=\log _{e} h_{0}(t)+\log _{e}\left[\exp \left(b_{1} x_{1}+b_{2} x_{2}+\cdots+b_{p} x_{p}\right)\right]
\end{gathered}
$$




$$
\log _{e}(h(t))=\log _{e} h_{0}(t)+b_{1} x_{1}+b_{2} x_{2}+\cdots+b_{p} x_{p}
$$

The quantities $\exp \left(b_{i}\right)$ are called hazard ratios (HR). A HR greater than one indicates that as the value of the $i^{\text {th }}$ covariate increases, the event hazard increases and thus, the survival time decreases. In summary:

$\mathrm{HR}=1$ : No effect;

$\mathrm{HR}<1$ : Reduction in the hazard;

$\mathrm{HR}>1$ : Increase in the hazard.

A covariate with HR greater than 1 is called a bad prognostic factor while a covariate with HR less than 1 is called a good prognostic factor.

For a categorical explanatory variable, a reference level (usually the first or last level of the variable) will be chosen and the other levels of the explanatory variable will be compared with the chosen reference level.

The Cox model assumes that the hazard ratio of any two individuals is constant over time.

\subsection{Test for the Proportionality Hazard Assumption}

The Cox model assumes that the hazard ratio between two respondents is independent of time. This assumption is called the proportionality hazard assumption. The proportionality hazard assumption is supported by a non-significant relationship between residuals and time. For each covariate, the scaled Schoenfeld residuals will be correlated with time to test for the independence between residuals and time. A global test will also be done for the model as a whole. The hypotheses for this test are given below:

$\mathrm{H}_{0}$ : There is no significant relationship between the residuals and time;

$\mathrm{H}_{1}$ : There is a significant relationship between the residuals and time.

The null hypothesis is rejected if the $\mathrm{p}$-value of the chi square test statistic for the correlation between the Schoenfeld residuals and time is less than $\alpha=0.05$ at 0.05 level of significance.

\section{Result}

All of the respondents in the study did not experience the event of interest (sexual intercourse). One of the respondents was censored while the other respondents in the study had sexual intercourse. Those surveyed are women between the ages of 15 - 49 years. First sexual intercourse started at age 8 years and about $54.4 \%$ of the respondents have had their first sexual intercourse before age 17 years. The median age of first sexual intercourse is 16 years which implies that about $50 \%$ of the respondents had their first sexual intercourse on or before their $16^{\text {th }}$ birthday. Figure 1 below is a summary of the age of first sexual intercourse of the respondents in this study and Figure 2 is the Kaplan-Meier plot of the age at first sexual intercourse. There was a sharp downward fall in the survival curve from age 12 20 years which implies that majority of the first sexual intercourse occur at this age group. All the respondents had their first sexual intercourse on or before their $37^{\text {th }}$ birthday except those that were censored because of the time limit of the study. 


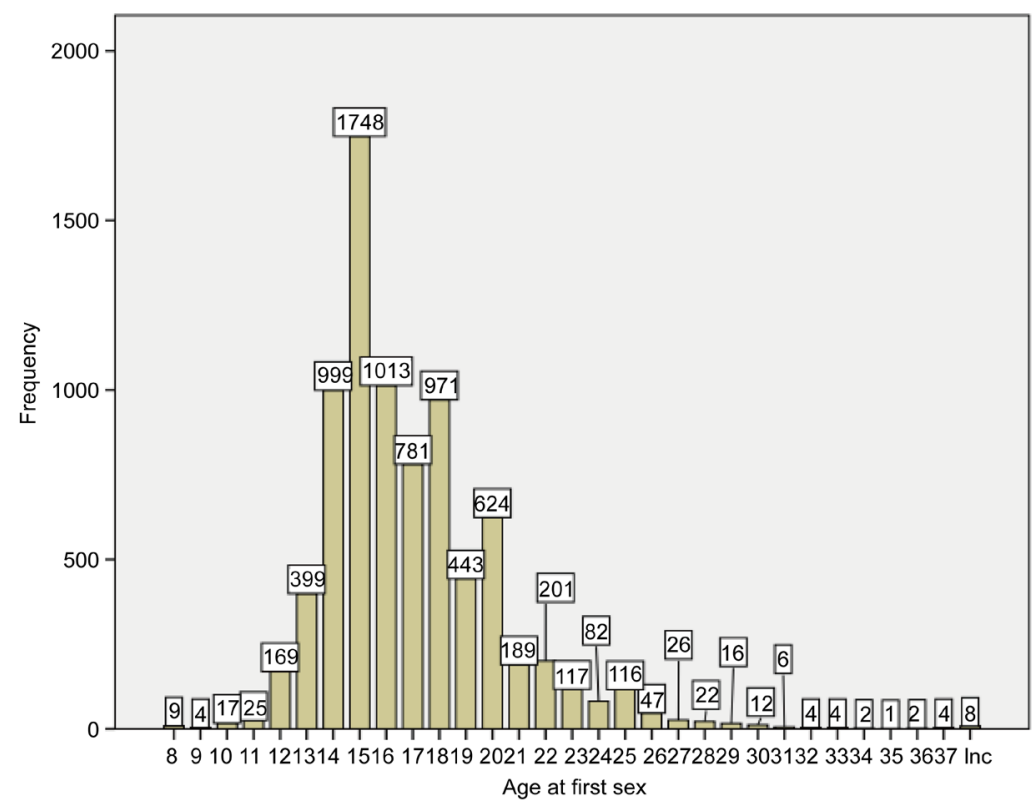

Figure 1. Age at first sex.

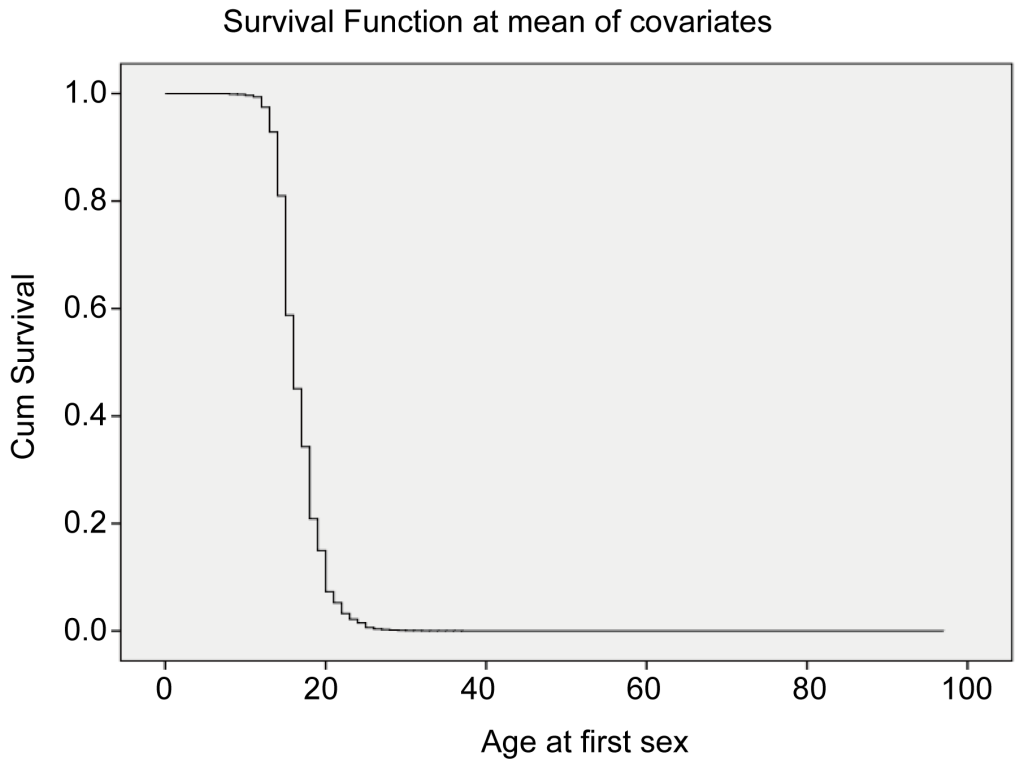

Figure 2. Kaplan-Meier plot of the age at first sexual intercourse.

The frequency distribution table of the five explanatory variables are given in Table 1 below. It shows us the number of respondents in each of the levels of the variables.

\subsection{Test for the Proportionality Hazard Assumption}

There is a non-significant relationship between residuals and time for all the explanatory variables since the probability values ( $\mathrm{p}$ values) of all the variables in Table 2 below are greater than 0.05 . This means that the proportionality hazard assumption is satisfied for all the explanatory variables. 
Table 1. Frequency distribution of the explanatory variables.

\begin{tabular}{|c|c|c|}
\hline & & Frequency \\
\hline \multirow{3}{*}{ Circumcision $^{\mathrm{b}}$} & $0=\mathrm{No}$ & 241 \\
\hline & $1=$ Yes & 7809 \\
\hline & $8=$ Don't know & 11 \\
\hline \multirow{4}{*}{ Educational_level ${ }^{\mathrm{b}}$} & $0=$ No education & 2430 \\
\hline & $1=$ Primary & 1425 \\
\hline & $2=$ Secondary & 2868 \\
\hline & $3=$ Higher & 1338 \\
\hline \multirow{4}{*}{ Religion $^{\mathrm{b}}$} & $1=$ Christian & 3450 \\
\hline & 2 = Islam & 4542 \\
\hline & $3=$ Traditionalist & 59 \\
\hline & $96=$ Other & 10 \\
\hline \multirow{6}{*}{ Region $^{\mathrm{b}}$} & $1=$ North Central & 1451 \\
\hline & $2=$ North East & 1574 \\
\hline & $3=$ North West & 2101 \\
\hline & $4=$ South East & 943 \\
\hline & $5=$ South South & 793 \\
\hline & $6=$ South West & 1199 \\
\hline \multirow{2}{*}{ Residence $^{\mathrm{b}}$} & $1=$ Urban & 3009 \\
\hline & $2=$ Rural & 5052 \\
\hline
\end{tabular}

Table 2. Relationship between residuals and time for all the explanatory variables.

\begin{tabular}{ccc}
\hline & rho & p value \\
\hline Circumcision & -0.00762 & 0.532 \\
Religion & 0.01038 & 0.442 \\
Region & 0.01676 & 0.156 \\
Residence & -0.0236 & 0.557 \\
Educational_level & 0.01935 & 0.210 \\
\hline
\end{tabular}

Since the proportionality hazard assumption is satisfied, we can proceed to estimating the parameters of the Cox model.

\subsection{The Cox Model}

The parameters of the Cox model were estimated by maximizing the partial likelihood and the results are given in Table 3. The first level of each of the categorical explanatory variables was used as the reference level and the other levels of the explanatory variable are compared to it. Table 3 also contains the $\mathrm{p}$ value of each level of the categorical explanatory variables that will be used to test for significant effect of the level. The exponent of the Cox model parameters gives us the odds of the variable. 
Table 3. Parameters of the Cox model.

\begin{tabular}{|c|c|c|c|c|c|c|}
\hline & & \multirow{2}{*}{ B } & \multirow{2}{*}{ Sig. } & \multirow{2}{*}{$\operatorname{Exp}(B)$} & \multicolumn{2}{|c|}{$95.0 \%$ CI for $\operatorname{Exp}(B)$} \\
\hline & & & & & Lower & Upper \\
\hline \multirow{3}{*}{ Circumcision } & No & & 0.265 & & & \\
\hline & Yes & 0.095 & 0.159 & 1.099 & 0.964 & 1.254 \\
\hline & Don't know & 0.336 & 0.276 & 1.400 & 0.764 & 2.564 \\
\hline \multirow{4}{*}{ Educational level } & No education & & 0.000 & & & \\
\hline & Primary & -0.084 & 0.020 & 0.920 & 0.857 & 0.987 \\
\hline & Secondary & -0.214 & 0.000 & 0.807 & 0.757 & 0.860 \\
\hline & Higher & -0.571 & 0.000 & 0.565 & 0.524 & 0.609 \\
\hline \multirow{4}{*}{ Religion } & Christianity & & 0.000 & & & \\
\hline & Islam & 0.145 & 0.000 & 1.156 & 1.085 & 1.232 \\
\hline & Traditionalist & 0.019 & 0.885 & 1.019 & 0.787 & 1.321 \\
\hline & Other & -0.153 & 0.630 & 0.858 & 0.461 & 1.598 \\
\hline \multirow{6}{*}{ Region } & North Central & & 0.000 & & & \\
\hline & North East & 0.249 & 0.000 & 1.283 & 1.191 & 1.382 \\
\hline & North West & 0.364 & 0.000 & 1.440 & 1.340 & 1.547 \\
\hline & South East & -0.190 & 0.000 & 0.827 & 0.755 & 0.907 \\
\hline & South South & 0.165 & 0.001 & 1.179 & 1.074 & 1.294 \\
\hline & South West & -0.213 & 0.000 & 0.808 & 0.746 & 0.876 \\
\hline Residence & Rural & 0.220 & 0.000 & 1.246 & 1.184 & 1.311 \\
\hline
\end{tabular}

There is no significant difference in the circumcision status of the respondent to the age at which they had their first sexual intercourse since the $\mathrm{p}$ values $(0.265$, 0.259 and 0.276 ) are greater than 0.05 . There is a significant effect of education on the age at first sexual intercourse ( $\mathrm{p}$ value $0.00<0.05$ ). The hazard of having an early sexual intercourse for those with primary, secondary and higher education decreases by $14.3 \%$ [ $(1-0.857) \times 100], 24.3 \%$ and $47.6 \%$ respectively when compared with those with no education. Being educated reduces the risk of having an early sexual intercourse.

The hazard of Muslims having sexual intercourse at an early age is 1.085 times that of Christians (the hazard increases by $8.5 \%$ ) but there is no significant difference in the effect of Christians with traditionalist and other religions since their $p$ values $(0.885$ and 0.630$)$ are greater than 0.05 .

The hazard of having sexual intercourse at an early age for those from North East, North West and South South is 1.382, 1.547 and 1.294 times respectively that of those from North Central (the hazard increases by $38.2 \%, 54.7 \%$ and $29.4 \%$ respectively) while the hazard of having early sexual intercourse for those from South East and South West is 0.755 and 0.746 times respectively that of those from North Central (the hazard decreases by $24.5 \%$ and $25.4 \%$ respectively when compared with those from North Central).

The hazard of those that live in rural areas having sexual intercourse at an early age is 1.184 times that of those that live in urban areas (the hazard increases by $18.4 \%)$. 


\section{Conclusions}

In this study, we have examined some socio-demographic and cultural factors and their relationship with age at first sexual intercourse. The result shows that educational level, religion, region and residence have a significant effect on the age at which individuals have their first sexual intercourse while circumcision has no significant effect. The results are in agreement with the findings of Anne B. (2009) [8] and Laura et al. (2019) [9].

We recommend that more sex education on the dangers of early age of first sexual intercourse should be introduced in schools, place of worship and residence of the teaming young population of Nigerian youths, especially, in the North-West, North-East and South-South geographical regions of the country.

\section{Conflicts of Interest}

The authors declare no conflicts of interest regarding the publication of this paper.

\section{References}

[1] Jokin, D.I., Alfonso, O., Silvia, C., Miguel, R. and Cristiana, L.B. (2011) Mean Age of First Sex: Do They Know What We Mean? Archives of Sexual Behavior, 40, 853-855. https://doi.org/10.1007/s10508-011-9779-4

[2] Upchurch, D.M., Mason, W.M., Kusunoki, Y. and Kriechbaum, M.J. (2004) Social and Behavioral Determinants of Self-Reported STD among Adolescents. Perspectives on Sexual and Reproductive Health, 36, 276-287.

https://doi.org/10.1363/3627604

[3] Campbell, A. (2008) The Morning after the Night before: Affective Reactions to One-Night Stands among Mated and Unmated Women and Men. Human Nature, 19, 157-173. https://doi.org/10.1007/s12110-008-9036-2

[4] Ma, Q., Ono-Kihara, M., Cong, L., Xu, G., Pan, X. and Zamani, S. (2009) Early Initiation of Sexual Activity: A Risk Factor for Sexually Transmitted Diseases, HIV Infection, and Unwanted Pregnancy among University Students in China. BMC Public Health, 9, Article No. 111. https://doi.org/10.1186/1471-2458-9-111

[5] Louie, K.S., De Sanjose, S., Diaz, M., Castellsague, X., Herrero, R. and Meijer, C.J. (2009) Early Age at First Sexual Intercourse and Early Pregnancy Are Risk Factors for Cervical Cancer in Developing Countries British. Journal of Cancer, 100, 1191-1197. https://doi.org/10.1038/sj.bjc.6604974

[6] Ugwuanyim, G.U., Osuchukwu, C.O., Bartholomew, D.C. and Obite, C.P. (2020) Medical Choices for a Wealthy Nation: A Multinomial Logistic Model. Asian Journal of Probability and Statistics, 6, 1-12. https://doi.org/10.9734/ajpas/2020/v6i330160

[7] Mercer, C.H., Aicken, C.R., Tanton, C., Estcourt, C.S., Brook, M.G., Keane, F. and Cassell, J.A. (2013) Serial Monogamy and Biologic Concurrency: Measurement of the Gaps between Sexual Partners to Inform Targeted Strategies. American Journal of Epidemiology, 178, 249-259. https://doi.org/10.1093/aje/kws467

[8] Anne, B. (2009) Age at Sexual Debut in South Africa. African Journal of AIDS Research, 4, 1-5.

[9] Laura, D.L., Isaac, M. and Arik, V.M. (2019) Prevalence of Sexual Initiation before 
Age 13 Years among Male Adolescents and Young Adults in the United States. JAMA Pediatrics, 173, 553-560. https://doi.org/10.1001/jamapediatrics.2019.0458

[10] Kann, L., McManus, T. and Harris, W.A. (2016) Youth Risk Behavior Surveillance: United States, 2015. MMWR Surveillance Summaries, 65, 1-174.

https://doi.org/10.15585/mmwr.ss6506a1

[11] Warner, T.D. and Settersten, R.A. (2017) Why Neighborhoods (And How We Study Them) Matter for Adolescent Development. In: Benson, J.B., Ed., Advances in Child Development and Behavior, Vol. 52, Elsevier Academic Press, Amsterdam, 105-152. https://doi.org/10.1016/bs.acdb.2016.10.003

[12] Lorraine, B., Saoirse, N.G. and Colette, K. (2018) Socio-Demographic, Health and Lifestyle Factors Influencing Age of Sexual Initiation among Adolescent. International Journal of Environmental Research and Public Health, 15, 1-15. https://doi.org/10.3390/ijerph15091851

[13] Frank, L.M., Michelle, M.F., Paul, N.H., Lori, K. and Elizabeth, G.M. (1996) The Determinant of First Sex by Age 14 in a High-Risk Adolescent Population. Family Planning Perspective, 28, 13-18. https://doi.org/10.2307/2135957 